\title{
Anoikis Resistance: An Essential Prerequisite for Tumor Metastasis
}

\author{
Yong-Nyun Kim, Kyung Hee Koo, Jee Young Sung, Un-Jung Yun, and Hyeryeong Kim \\ Pediatric Oncology Branch, National Cancer Center, 323 Ilsan-Ro, Ilsandong-Gu, Gyeonggi-Do, Goyang-Si 410-769, Republic of Korea \\ Correspondence should be addressed to Yong-Nyun Kim, ynk@ncc.re.kr
}

Received 21 October 2011; Accepted 3 December 2011

Academic Editor: Motoharu Seiki

Copyright ( $) 2012$ Yong-Nyun Kim et al. This is an open access article distributed under the Creative Commons Attribution License, which permits unrestricted use, distribution, and reproduction in any medium, provided the original work is properly cited.

\begin{abstract}
Metastasis is a multistep process including dissociation of cancer cells from primary sites, survival in the vascular system, and proliferation in distant target organs. As a barrier to metastasis, cells normally undergo an apoptotic process known as "anoikis," a form of cell death due to loss of contact with the extracellular matrix or neighboring cells. Cancer cells acquire anoikis resistance to survive after detachment from the primary sites and travel through the circulatory and lymphatic systems to disseminate throughout the body. Because recent technological advances enable us to detect rare circulating tumor cells, which are anoikis resistant, currently, anoikis resistance becomes a hot topic in cancer research. Detailed molecular and functional analyses of anoikis resistant cells may provide insight into the biology of cancer metastasis and identify novel therapeutic targets for prevention of cancer dissemination. This paper comprehensively describes recent investigations of the molecular and cellular mechanisms underlying anoikis and anoikis resistance in relation to intrinsic and extrinsic death signaling, epithelial-mesenchymal transition, growth factor receptors, energy metabolism, reactive oxygen species, membrane microdomains, and lipid rafts.
\end{abstract}

\section{Introduction}

Development, differentiation, and homeostasis are controlled by cell-cell interactions, cell-extracellular matrix (ECM) interactions, and soluble cues (hormones, cytokines, and growth factors) $[1,2]$. Cell adhesion to ECM occurs through interactions between specific integrin receptors and ECM counterparts. These interactions cause the transduction of many different signals that regulate cellular functions, such as gene expression, differentiation, proliferation, and motility. Importantly, an appropriate adhesion to ECM components determines whether a cell is in the correct location and thus regulates cell survival and cell death. In 1994, Frisch and Francis noticed that loss of matrix attachment of epithelial cells resulted in apoptosis [3]. They referred to this form of programmed cell death that occurs upon detachment from the appropriate ECM as anoikis [4-6]. Because anoikis prevents detached epithelial cells from colonizing elsewhere, thereby inhibiting dysplastic cell growth or attachment to an inappropriate matrix, anoikis is a physiologically relevant process for tissue homeostasis and development. Dysregulation of anoikis, such as anoikis resistance, is a critical mechanism in tumor metastasis. Epithelial cancers initially arise as an organ-confined lesion, but eventually spread to distinct organs through the bloodstream, generating metastatic lesions that are responsible for most cancer-related lethality. The tumor cells that acquire anoikis resistance can survive after detachment from their primary site and while traveling through the vascular system until they colonize the distal organ [4-7]. In addition, anoikis resistance is also important for the peritoneal dissemination of gastric and ovarian cancer cells $[6,8]$. This paper will focus on the current understanding of cellular and molecular mechanisms of anoikis resistance.

\section{Adhesion and Cell Survival}

For survival and proliferation, normal epithelial cells require adhesion to specific ECM components through cell surface receptors known as integrins. Integrins are heterodimers consisting of $\alpha$ - and $\beta$-subunits. There are at least 24 distinct integrin heterodimers assembled by the combination of 18 
$\alpha$-subunits and $8 \beta$-subunits. Because specific integrin heterodimers preferentially bind to distinct ECM components, the repertoire of integrins on the cell surface guides where the cell adheres or migrates. Integrin expression patterns vary between normal tissue and tumors $[1,6,9]$. Although integrins $\alpha v \beta 1, \alpha 5 \beta 1$, and $\alpha v \beta 6$ are usually expressed at low levels, they are highly upregulated in some tumors, whereas some integrins, such as $\alpha 2 \beta 1$, are decreased in tumor cells. Integrin ligation regulates not only cell adhesion and migration but also cell survival. Ligated integrins transduce survival signals, whereas unligated integrins can promote a proapoptotic cascade, thereby preventing cells from surviving in an inappropriate environment [2].

Integrins activate multiple signaling pathways that regulate cell motility and survival through interactions with cytoplasmic kinases, small G-proteins, and scaffolding proteins. Integrin ligation activates FAK, a nonreceptor tyrosine kinase, and activated FAK phosphorylates itself and other cellular proteins. FAK autophosphorylation at Y397 provides a binding site for $\mathrm{SH} 2$ domain-containing proteins such as Src family kinases and the p85 subunit of PI3K, which is important for integrin-mediated cell growth and migration $[2,6]$. Integrin ligation activates the NF- $\kappa \mathrm{B}$ and $\mathrm{PI} 3 \mathrm{~K} / \mathrm{Akt}$ pathways and upregulates prosurvival proteins, Bcl-2 and FLIP, thereby enhancing cell survival [10]. Crosstalk between growth factor receptors and integrins activates Raf, which also promotes cell survival [6]. Although cell adhesion is critical for cell growth in normal tissues, adhesion-dependent control of cell growth is dysregulated in tumor cells, as anchorage-independent growth is prominently implicated in malignant transformation.

Recently, CUB domain-containing protein 1 (CDCP1), a transmembrane glycoprotein, has been linked to a noble pathway of anoikis resistance independent of Ras-MAPK and PI3K-Akt pathways in lung cancer and gastric cancer cell lines $[11,12]$. Cell detachment induces CDCP1 phosphorylation by Src family kinases (SFKs) including Src, Fyn, and Yes. Upon SFK-mediated tyrosine phosphorylation of CDCP1, PKC $\delta$ forms a complex with CDCP1 and SFKs, is phosphorylated by SFKs and activated, leading to anoikis resistance [12]. Interestingly, CDCP1 phosphorylation by SFKs further activates SFKs and enhances metastasis in melanoma, indicating a "feed-forward loop" to maintain elevated activity of SFKs during tumor progression although the cause of the initial activation of SFKs is not clear $[11,13]$.

Resistance to detachment-induced cell death, or anoikis resistance, is emerging as a hallmark of metastatic malignancies, because it can ensure anchorage-independent growth and survival during tumor dissemination [4-6]. Numerous studies have suggested that stimulation of prosurvival signals and suppression of death signals are involved in anoikis resistance.

\section{Prosurvival Signals and Apoptotic Signals in Anoikis Resistance}

The role of the death receptor and the mitochondrial pathway in anoikis and anoikis resistance has been reviewed recently [5]. The death receptor (extrinsic) pathway is initiated by ligation of members of the TNF receptor superfamily, such as Fas and TNF-R1, causing the formation of the death-inducing signaling complex (DISC) as described in the Figure 1. Upon DISC formation, caspase8 (FLICE) is activated and released into the cytoplasm where it cleaves caspase-3 and caspase-7. These activated effector caspases cleave cellular substrates, culminating cell death. FLIP (FLICE-inhibitory protein) has a higher affinity for the DISC than caspase- 8 and is preferentially recruited to the DISC, thereby inhibiting caspase- 8 recruitment and activation $[5,14,15]$. Anoikis employs this extrinsic pathway, at least partially. For example, matrix attachment protects cells from Fas-induced apoptosis, whereas matrix detachment sensitizes cells to Fas-mediated apoptosis. After cell detachment, FasL and Fas receptor are upregulated but FLIP, an endogenous antagonist of caspase-8, is downregulated, which leads to caspase- 8 activation in human umbilical vein cells (HUVECs) [16, 17]. In addition, unligated integrin recruits caspase- 8 to the membrane, where it becomes activated in a death receptor-independent manner, whereas integrin ligation disrupts this integrin-caspase complex and increases survival [18]. Caspase-8 activation triggers anoikis but FLIP overexpression, which inhibits caspase- 8 activation and blocks anoikis in keratinocytes and HUVECs [16, 17]. Malignant cells avoid anoikis by overexpressing FLIP [5]. Anisomycin can sensitize cells to anoikis by decreasing FLIP protein levels and inhibits distal tumor formation in a mouse model of prostate cancer metastasis [19].

In the mitochondrial (intrinsic) pathway, proteins of the Bcl-2 family are key players and include anti-apoptotic proteins, such as $\mathrm{Bcl}-2, \mathrm{Bcl}-\mathrm{xL}$, and $\mathrm{Mcl}-1$, and proapoptotic proteins, such as the $\mathrm{BH} 3$-only proteins Bid, Bad, Noxa, Puma, and Bim, as well as Bax, Bak, and Bok [20]. In response to death signals, monomeric Bax or Bak translocate from the cytosol to the outer mitochondrial membrane (OMM) where they form oligomers, causing mitochondrial permeabilization and release of cytochrome $c$ and Smac/DIABLO. Released cytochrome c triggers caspase- 9 activation and consequently caspase- 3 activation. Smac/DIABLO impedes the function of inhibitor of apoptosis proteins, IAP and XIAP. Bcl-2 exerts its antiapoptotic function by binding to pro-apoptotic proteins, Bax and Bad, preventing their oligomerization and thus maintaining mitochondrial membrane integrity. $\mathrm{BH} 3$-only proteins compete with $\mathrm{Bcl}-2$ for binding with apoptotic activators, thus promoting apoptosis [21].

The mitochondrial (intrinsic) pathway is activated during anoikis. Bid translocates to the OMM following loss of adhesion with identical kinetics with Bax, which is required for anoikis of mammary epithelial cells [22]. Bim is sequestered by dynein cytoskeletal complexes when cells are attached to ECM. Cell detachment induces release of Bim from these complexes and causes its translocation to the mitochondria, where it interacts with $\mathrm{Bcl}-\mathrm{xL}$, neutralizing its prosurvival function $[23,24]$. Loss of cell adhesion also causes the accumulation of cytoplasmic Bim via inhibiting its proteasomal degradation initiated by its phosphorylation through the ERK and PI3K/Akt pathways. Activated Bim promotes Bax-Bak oligomerization within the OMM and 


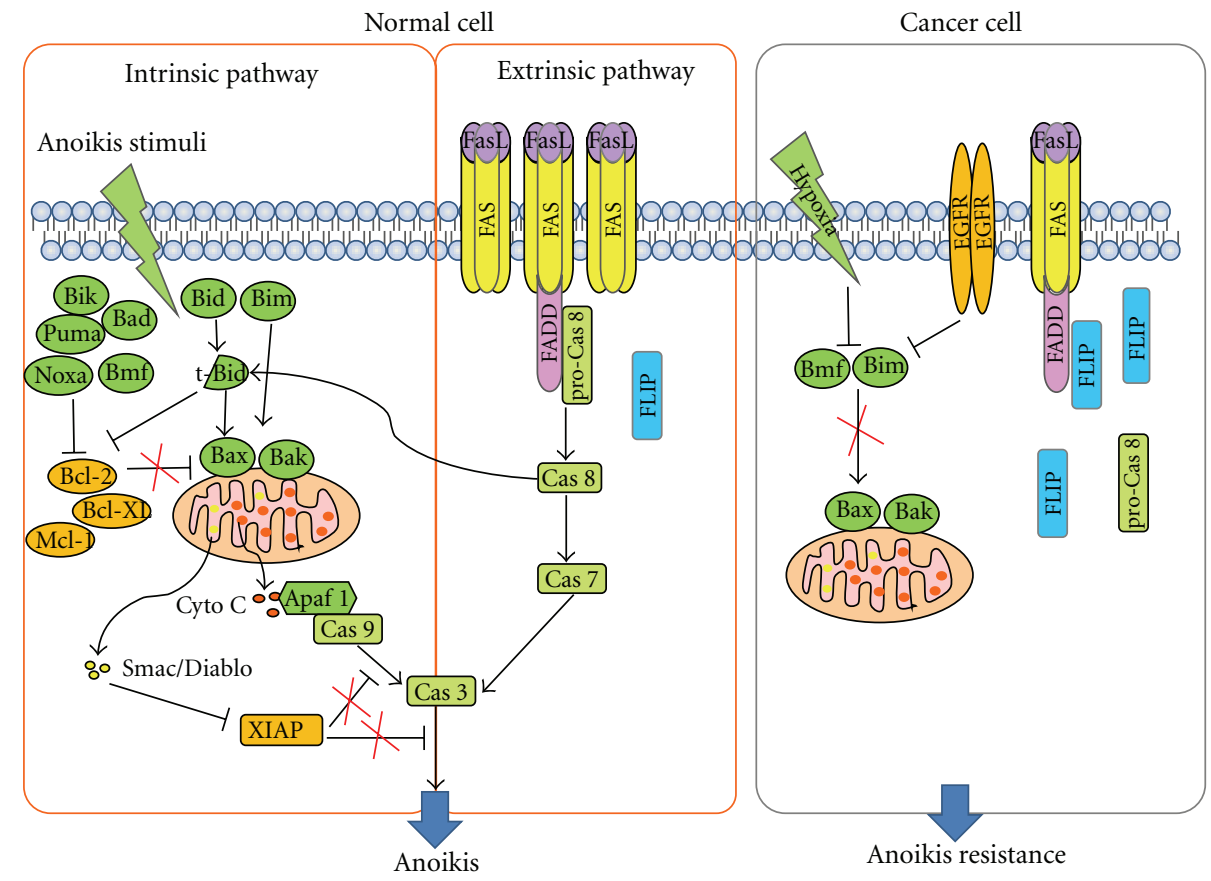

FIGURE 1: Schematic representation of intrinsic and exrtinsic pathways of anoikis. When cells are detached from ECM, normal cells induce anoikis through both intrinsic and exrtinsic pathways. Upon cell detachment, FAS and FasL are upregulated and FLIP is downregulated, leading to activation of Caspase 8 , followed by activation of caspase-7 and caspase-3. Loss of cell adhesion also increases and activates proapoptotic Bcl-2 proteins (Bik, Puma, Bad, Noxa, Bmf, Bid, Bim, Bax, and Bak), which inactivate antiapoptotic Bcl-2 proteins (Bcl-2, $\mathrm{Bcl}-\mathrm{xL}, \mathrm{Mcl}-1)$, and thus causing mitochondria membrane permeabilization through Bax/Bak oligomerization. Released cytochrome $\mathrm{c}$ from mitochondria activates caspase-9, subsequently caspase-3. Smac/DIABLO is released and inhibits XIAP, an inhibitor of apoptosis, leading to caspase-3 activation. Activaiton of these pathways leads to anoikis. However, increased FLIP expression in cancer cells inhibits extrinsic pathway and oncogene expression such as EGFR and hypoxia downregulate Bmf and Bim, resulting in inhibition of mitochondrial pathway in suspended cells. Accordingly, cancer cells acquire anoikis resistance.

induces intrinsic apoptosis pathway upon cell detachment [4, 24]. Bcl-2 modifying factor (BMF) is sequestered to myosin $\mathrm{V}$ motor complexes and, upon loss of cell attachment, is released. BMF then binds to antiapoptotic $\mathrm{Bcl}-2$ to initiate anoikis in human intestinal epithelial cells $[4,25,26]$. Both Bim and BMF are associated with cytoskeletal structures and counteract the activity of antiapoptotic $\mathrm{Bcl}-2$ when cell adhesion is disrupted. Therefore, suppression of Bim and BMF could confer anoikis resistance. In fact, overexpression of EGFR blocks both Bim expression and anoikis [27] and hypoxia decreases Bim and BMF expression and blocks anoikis in mammary epithelial cells [28].

\section{EMT and Anoikis Resistance}

During metastasis, epithelial cancer cells are released from their environment by breaking the basement membrane barrier. This process is involved in epithelial-mesenchymal transition (EMT). EMT is the biological process through which polarized epithelial cells undergo multiple biochemical changes, leading to a mesenchymal phenotype, such as enhanced migratory capacity, invasiveness, and resistance to apoptosis [29]. EMT is an essential process during development and is also induced during tissue repair and pathological processes, including inflammation and highgrade carcinomas in adults. EMT is characterized by loss of several epithelial proteins, including E-cadherin, $\beta$-catenin, and $\gamma$-catenin. It is also accompanied by increased expression of mesenchymal proteins, such as $\mathrm{N}$-cadherin, vimentin, fibronectin, and smooth muscle actin. The significance of Ecadherin loss in metastasis has been shown in a variety of in vitro and in vivo models $[30,31]$ and loss of E-cadherin is the major hallmark of EMT. Loss of E-cadherin may be achieved through the upregulation of transcriptional repressors of Ecadherin, including E12/E47, Twist, and members of the Zeb and Snail protein families. Transforming growth factor- $\beta$ (TGF- $\beta$ ), an inducer of EMT, upregulates these transcription factors, thereby promoting EMT and metastasis $[32,33]$.

EMT is not only a key event for epithelial-derived cells to acquire a motile and invasive phenotype but also an essential process for anoikis resistance [34]. EMT-promoting proteins are linked to anoikis resistance. Loss of E-cadherin induces anoikis resistance and promotes metastasis and $\mathrm{N}$-cadherin expression also induces anoikis resistance [35]. Twist is the mediator of loss of E-cadherin-induced anoikis resistance $[36,37]$. Conditional knockdown of E-cadherin and p53 in mammary epithelium induces mammary tumor initiation, metastasis, and anoikis resistance in the mouse model [37]. Moreover, the loss of E-cadherin induces Twist expression, indicating a feed-forward loop to maintain EMT [38]. Neurotrophic tyrosine kinase receptor B (TrkB) induces EMT, 
and knockdown of Twist blocks TrkB-induced EMT, anoikis resistance, and tumor growth. Moreover, Snail was induced by Twist, and silencing of Snail impairs EMT and anoikis resistance [39]. Twist is upregulated in several malignancies and promotes EMT, and Zeb and Snail are often overexpressed in metastasizing tumors $[36,40]$. Knockdown of Zeb1 induces E-cadherin expression and inhibits cell growth in anchorage-independent conditions [41]. Zeb1, acting downstream of Twist and Snail, is also required for TrkBinduced EMT, anoikis resistance, and metastasis [42]. The E-cadherin-interacting protein, ankyrin-G, mediates anoikis regulatory signals, and binds with neurotrophin receptorinteracting MAGE homolog (NRAGE). NRAGE represses the p14ARF gene and suppresses anoikis [43]. Recently, Shin et al. [44] reported that activation of EKR2 but not EKR1 is necessary for Ras-induced EMT in MCF-10A cells that are transformed by oncogenic Ras. ERK2 activation results in the Fral upregulation, which in turn triggers the accumulation of Zeb1/2, thereby inducing EMT and increasing migration, invasion, and survival. In addition, TGF- $\beta$ induces EMT via isoform switching of FGF receptors, causing the cells to be more sensitive to FGF-2, which activates the MEKERK pathway to regulate complex formation of Zeb1 with transcription corepressor CtBP1 [45].

During the EMT process, E-cadherin expression is downregulated whereas $\mathrm{N}$-cadherin expression is up-regulated, referred to as a "cadherin switch" [46]. E/N-cadherin switch promotes cancer progression via TGF- $\beta$-induced EMT in extrahepatic cholangiocarcinoma [47]. N-cadherin expression appears to be more critical for tumor malignancy than E-cadherin. N-cadherin promotes cell motility and invasion via interactions with growth factor receptors such as FGF receptors and PDGF receptor. $\mathrm{N}$-cadherin also promotes cell growth and survival by repressing apoptotic signals and numerous clinical studies have shown that aggressive human tumors express $\mathrm{N}$-cadherin in situ, indicating a critical role for cadherin switch in human tumorigenesis [48]. Accordingly, both EMT and anoikis resistance are key processes for metastasis and they share common regulators, such as Twist, Snail, Zeb1, E-cadherin, and N-cadherin (Figure 2).

\section{Growth Factor Receptors and Anoikis Resistance}

Unregulated expression of growth factor receptors or components of their signaling pathways are associated with tumor malignancy due to their inhibition of cell death pathways and activation of cell survival pathways [49]. Abnormal regulation of growth factor receptors activates prosurvival signaling pathways, such as the PI3K/Akt, Ras/MAPK, NF$\kappa \mathrm{B}$, and Rho-GTPase pathways $[1,49]$, leading to metastasis by inhibiting anoikis. This can be achieved through autocrine signaling of growth factors, including fibroblast growth factor (FGF), hepatocyte growth factor (HGF), and plateletderived growth factor (PDGF). In addition, overexpression of growth factor receptors, such as EGF receptor, TrkB receptor, and HGF receptor, can suppress anoikis.

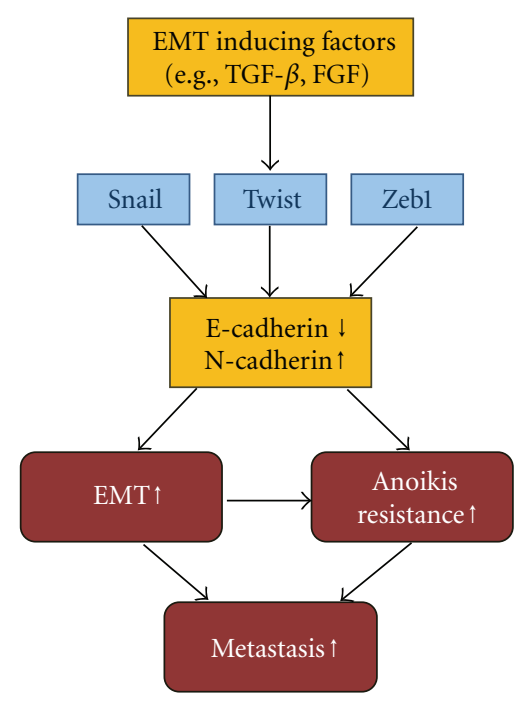

FIGURE 2: Schematic representation of EMT and anoikis resistance. EMT-inducing factors, such as TGF- $\beta$ and FGF activate transcriptional factor, Twist, Snail and Zeb1. Activated these transcriptional factors repress E-cadherin (encoded $\mathrm{CDH} 1$ gene) expression and induce N-cadherin expression (Cadherin switch). Cadherin switch induces EMT and anoikis resistance, which are associated with tumor metastasis.

ErbB family members are tightly linked to tumor progression and malignancies through the activation of many different signaling pathways for cell proliferation, survival, and migration [49]. Upon detachment from ECM, EGFR (ErbB1) is downregulated and Bim is upregulated, which is a critical mechanism for anoikis. Overexpression of EGF receptor maintains ERK activation in suspended cells and blocks anoikis via suppression of Bim expression in MCF$10 \mathrm{~A}$ cells, indicating that growth factor receptor expression uncouples anoikis from integrin regulation [27]. Moreover, ErbB2 overexpression blocks Bim expression and anoikis, via upregulation of $\alpha 5$ integrin and activation of Src in ECMdetached cells [50]. Loss of ECM attachment downregulates EGF receptor and $\beta 1$ integrin both at the protein and mRNA levels. However, ErbB2 overexpression rescues both EGF receptor and $\beta 1$ integrin protein via ERK and Sprouty, which stabilizes EGF receptor in ECM-detached cells [51]. Cell detachment causes ATP deficiency due to the decreased glucose transport but this deficiency can be rescued by ErbB2 overexpression, which stabilizes EGF receptor expression and thus PI3K activation [52]. TGF- $\alpha$, a ligand for EGF receptor, prevents anoikis of intestinal epithelial cells by reversing the loss of Src activity and Bcl-xL expression induced by cell detachment [53]. Anchorage-independent Ewing sarcoma cells suppress anoikis through a pathway involving Ecadherin cell-cell adhesion, which leads to ErbB4 activation of the PI3K/Akt pathway [54]. The PI3K/Akt pathway plays a critical role in cell survival and PTEN, one of the most frequently mutated tumor suppressors in human cancer, negatively regulates the PI3K/Akt pathway [55]. PTEN also plays an important role in the anoikis induction through negative regulation of FAK. Overexpression of PTEN induces 
anoikis via suppression of the phosphorylation of FAK and Akt in human bladder transitional carcinoma cells [56] and in U251 glioma cells [57]. Accordingly, loss of PTEN confers apoptotic resistance to cell rounding and matrix detachment in human mammary epithelial cells [58].

Insulin-like growth factor 1 (IGF-1) is a well-established cell survival factor that triggers Akt activation after loss of matrix contact [59]. IGF-1 receptor prevents anoikis in mouse embryo fibroblasts [60] and in the LNCaP human prostate epithelial cell line [59]. Disruption of IGF-1 receptor signaling decreased the number of circulating tumor cells in the blood of tumor-bearing mice and enhanced anoikis of LCC6 cells, a metastatic variant of MDA-MB-435 breast cancer cells [61]. Many studies have reported that PDGF receptor is also associated with metastasis of tumor [62-64]. PDGF receptor acts as the upstream tyrosine kinase for $\mathrm{Src}$, a key contributor for anoikis resistance, in a human lung adenocarcinoma upon cell detachment [65]. The cooperation of autocrine PDGF-PDGFR signaling with oncogenic Ras strongly activates $\mathrm{PI} 3 \mathrm{~K}$ and is required for survival during EMT [66]. Transforming growth factor- $\beta$ (TGF- $\beta$ ) and its receptor also play critical roles in tumor progression and metastasis. TGF- $\beta 1$ coordinately and independently activates FAK and Akt kinase pathways through the early activation of SMAD3 and p38 MAPK, respectively, to confer an anoikis resistant phenotype to myofibroblasts [67]. In addition, in conjunction with EGF, TGF- $\beta 1$ enhances migration, invasion, and anchorage-independent growth compared to that induced by EGF alone through the activation of MAPK and Akt [68]. Accordingly, the TGF- $\beta$ inhibitor, LY2109761, suppresses metastasis of pancreatic cancer by inducing anoikis [69]. Conditional activation of FGF receptor causes anchorage-independent growth and EMT in a ribosomal S6 kinase-dependent manner in MCF-10A cells [70]. HGF and its receptor inhibits anoikis of pancreatic carcinoma cells through the PI3K pathway and of head and neck squamous carcinoma cells through activation of ERK and Akt signaling $[71,72]$. Vascular endothelial growth factor A (VEGF-A) and its main signaling-receptor VEGFR2 (KDR) are expressed in primary ovarian tumors and autocrine VEGF-A/KDR loop protects ovarian carcinoma cells from anoikis [73].

\section{Energy Metabolism, Autophagy, ROS, and Anoikis Resistance}

Rapidly dividing tumor cells require rapid ATP generation, increased biosynthesis of biomolecules, and maintenance of an appropriate redox status to support cell division, despite the low oxygen (hypoxia) and nutrient levels within the tumor [74]. Tumor cells reprogram their metabolic pathways to meet these needs. The best-characterized metabolic phenotype in tumor cells is marked by the Warburg effect, which is a shift from ATP generation through oxidative phosphorylation to ATP generation through glycolysis, even under normal oxygen concentrations [75]. This aerobic glycolysis is regulated by $\mathrm{PI} 3 \mathrm{~K} / \mathrm{Akt}[76,77]$, hypoxia-inducible factor (HIF) [78-82], p53 [83-85], Myc [77, 86, 87], and AMPactivated protein kinase (AMPK)-liver kinase B1 (LKB1)
[88-90] pathways. Alternatively, stress conditions, such as limited nutrients and hypoxia, activate autophagy to buffer metabolic stress during tumor growth [91].

An elegant model for the study of anoikis has been developed and provides insight into the mechanisms of detachment-induced apoptosis. Three dimensional culture of MCF-10A mammary epithelial cells form spheroid structures, termed acini, in which a layer of polarized epithelial cells surrounds a hollow lumen, resembling glandular epithelium in vivo. This lumen formation involves the clearance of central cells by selective anoikis of cells lacking ECM attachment [91]. When MCF-10A cells are detached from the ECM, glucose uptake is decreased, energy production is reduced [52]. Overexpression of ErbB2 has been linked to anoikis resistance. In line with this report, overexpression of ErbB2 rescues ATP deficiency by restoring glucose uptake through EGF receptor stabilization and PI3K activation, which is consistent with the studies that the PI3K/Akt pathway activates glucose uptake and protects cancer cells from starvation $[52,92]$. Lack of glucose uptake in the detached cells blocks both glycolysis and the pentose phosphate pathway (PPP). In addition to macromolecular building blocks, PPP produces NADPH, a crucial cellular reducing agent, quenching the reactive oxygen species (ROS) produced during cell metabolism [74]. Accordingly, in the detached cells, ROS levels are increased and antioxidant treatment rescues low ATP levels by permitting fatty acid oxidation, leading to the filling of the luminal space in MCF-10A acini. An increase in oxidative damage blocks the consumption of fatty acids for energy production, and thus detached epithelial cells experience severe starvation and death. However, expression of the ErbB2 oncogene enables MCF-10A cells to overcome anoikis because there is enough ATP production with continuous glucose uptake.

Autophagy is a tightly regulated lysosomal self-eating process that is upregulated during cellular stress, such as deprivation of nutrients and growth factors. Autophagy produces nutrients and energy to enhance cell survival through the breakdown of cytosolic components. Basal levels of autophagy are required to maintain homeostasis by removing damaged proteins and organelles. Although autophagy is essential for cell survival, excessive autophagy results in programmed cell death. Autophagy is regulated by autophagy-related genes (ATGs), and the majority of proautophagic events converge on the mammalian target of rapamycin (mTOR) pathway [93]. Autophagy is known to suppress tumor formation by limiting chromosomal instability and promoting cellular senescence [94]. In contrast, protumorigenic functions for autophagy have been proposed and demonstrated. Autophagy is increased in cancer cells during many of the conditions directing metastasis, including hypoxia, metabolic stress, and cell detachment from ECM [93]. Silencing of autophagy regulators inhibits detachment-induced autophagy and enhances apoptosis, indicating that autophagy promotes epithelial cell survival during anoikis [91]. Recently, it was reported that oncogenic $\mathrm{H}$-Ras expression induces autophagy upon cell detachment [95]. Interestingly, genetic deletion or RNAi-mediated knockdown of autophagy regulators decreases cell growth 
in soft agar and reduces glycolysis, indicating that an intact autophagy pathway is required for adhesion-independent transformation and facilitates glycolysis through oncogenic H-Ras [95]. These studies suggest that anoikis resistance is associated with tolerance to bioenergetic stress due to oncogene expression.

The balance between oxidation and reduction plays a critical role in the cellular signaling pathways involved in cell growth and metastasis. Elevated oxidative stress is more frequently observed in many solid tumors and carcinoma cell lines than in normal cells. ROS are now recognized as key second messengers during growth factor and cytokine stimulation to elicit prosurvival signals. Upon integrin engagement, ROS are produced via Rac-1, and elevated ROS induce prosurvival signaling through Src activation. Activated Src phosphorylates EGF receptor in a ligandindependent manner, which activates the ERK and Akt pathways, leading to Bim degradation and suppression of anoikis. Src activation plays a critical role in anoikis resistance. Src is transiently activated upon cell detachment, which delays anoikis in intestinal epithelial cells [96]. In addition, in metastatic prostate cancer cells, ROS are constitutively produced due to sustained activation of 5-lopoxigenase (5LOX). These amplified and persistent redox signals activate Src in the absence of adhesion, thereby sustaining ligandindependent EGFR activation. This pathway degrades proapoptotic protein Bim, thereby promoting anoikis resistance [97]. Elevated expression of angiopoietin-like 4 (ANGPTL4) is widespread in tumors and its role in anoikis resistance has been recently reported [98]. ANGPTL4 binds to $\beta 1$ and $\beta 5$ integrins directly, which stimulates NADPH oxidase (NOX)dependent production of $\mathrm{O}_{2}^{-}$. A high ratio of $\mathrm{O}_{2}^{-}: \mathrm{H}_{2} \mathrm{O}_{2}$ activates Src, triggering the prosurvival PI3K/Akt and ERK pathways to confer anoikis resistance.

\section{Membrane Microdomains and Anoikis Resistance}

Another way to regulate anoikis is through modulation of membrane microdomains, including lipid rafts. This topic was recently reviewed [99]. There are two distinct types of lipid rafts: planar lipid rafts (noninvaginated rafts) and invaginated rafts known as caveolae. Caveolae are characterized by specific scaffolding proteins, called caveolins. Sphingolipids and cholesterol are the major lipid components of lipid rafts, and cholesterol is critical for the intact structure of lipid rafts. Because cell surface receptors, such as integrins and growth factor receptors, and some intracellular signaling molecules are enriched in lipid rafts, lipid rafts are regarded as the sites of assembly and initiation of signaling pathways $[100,101]$.

Caveolin-1, a structural protein for caveolae, acts as a scaffolding protein via its binding to signaling molecules such as EGF receptor, Src family members, MAPK, PKC, endothelial nitric oxide synthase (eNOS), and G-protein $\alpha$ subunits through its scaffolding domain [101]. This binding is known to negatively regulate these molecules. Initially, caveolin-1 was regarded as a tumor suppressor because it is downregulated in transformed cells and re-expression of caveolin-1 inhibits colony formation and induces apoptosis in transformed cells and breast cancer cells [102]. However, caveolin-1 levels are elevated in prostate cancer and lung adenocarcinomas, and the elevated caveolin-1 levels are associated with increased metastatic capacity and poor prognosis [103, 104], indicative of an oncogenic role for caveolin-1. Several studies have demonstrated that caveolin-1is associated with anchorage-independent growth. Caveolin-1 expression inhibits anoikis by inhibiting p53 activation and activating IGF receptor-mediated ERK and Akt signaling pathways upon cell detachment [105]. In human lung carcinoma $\mathrm{H} 460$ cells, caveolin-1 is downregulated during cell detachment through a mechanism involving ubiquitin-mediated proteasomal degradation. Interestingly, nitric oxide (NO) prevents downregulation of caveolin1 by ubiquitination and this event suppresses anoikis [106]. Alternatively, increased levels of hydrogen peroxide in detached cells prevent caveolin-1 degradation and stabilize it, thereby inhibiting anoikis [107]. Overall, caveolin-1 appears to have dual functions depending on the cell type: as a tumor suppressor by inhibiting anchorage-independent cell growth and as a promoter of tumor metastasis by preventing anoikis.

Lipid rafts are associated with integrin signaling. Thus, modulation of lipid rafts is linked to adhesion-dependent cell survival. Cell detachment triggers internalization of lipid rafts, and inhibition of lipid raft internalization maintains Rac1 membrane targeting and downstream effector activation in suspended cells [108]. This study indicates that integrins regulate lipid raft localization, thereby controlling anchorage-dependent cell growth. In line with this notion, disruption of lipid rafts by cholesterol depletion results in FAK down-regulation, cell detachment, lipid raft internalization, and anoikis-like cell death in A431 human cervical cancer cells $[109,110]$. Lipid raft disruption induces tyrosine phosphorylation of caveolin-1 through Src activation, which could be involved in lipid raft internalization. Caveolin-1 is tyrosine phosphorylated by Src and EGF-receptor signaling $[99,111]$, and this phosphorylation has been shown to be involved in caveolae internalization [112]. Under lipid raft disrupting stress, HIF- $1 \alpha$ is induced via EGF receptor activation, which delays anoikis. This is consistent with the finding that knockdown of HIF- $1 \alpha$ accelerates anoikis [113]. Aloe-emodin is an anthraquinone derivative that alters lipid rafts by decreasing sphingolipid and cholesterol in the lipid raft fraction. It inhibits tumor cell adhesion through disruption of the lipid raft-associated integrin signaling pathways, such as FAK recruitment to $\beta 1$ integrin [114] and it sensitizes anoikis in gastric carcinoma cells and lung cancer $\mathrm{H} 460$ cells $[115,116]$. Akt activation is important for cell survival and anoikis resistance [4]. Intact lipid rafts are critical for PI3K/Akt signaling because they facilitate Akt recruitment and activation upon phosphatidylinositol3,4,5-triphosphate accumulation in the membrane [117]. Lipid rafts disruption by cholesterol depletion results in both lipid raft internalization and Akt inactivation even in the presence of EGF stimulation. Cholesterol repletion reverses these effects $[109,110]$, indicating that lipid raft localization in the plasma membrane is important for Akt activation. 
It is possible that metastatic tumor cells possess a mechanism to regulate lipid raft localization to escape anoikis, which remains to be investigated further.

\section{Conclusion}

Normal epithelial cells require adhesion to the appropriate ECM for survival and proliferation, and loss of this adhesion induces a type of cell death known as anoikis. Anoikis is important for normal development and tissue homeostasis because it prevents detached cells from reattaching to an inappropriate ECM and growing dysplastically. Anoikis resistance, or survival in the absence of attachment to ECM, is a prerequisite for the development of tumor metastases, the major cause of cancer mortality. Currently, anoikis dysregulation or resistance has evoked special attention in the cancer research fields because circulating tumor cells in the blood stream are resistant to anoikis, which allows the cancer cells to disseminate from the primary tumor site to a distinct lesion. Anoikis is regulated by many different signaling pathways depending on the cell type and expressed oncogenes. Both the intrinsic and extrinsic death pathways are employed in anoikis. Expression of oncogenes, such as ErbB family members, is enable cells to avoid anoikis by inhibiting apoptotic pathways. In this paper, we included current data on the mechanisms of anoikis in relation to alterations of energy metabolism, autophagy, ROS, and lipid rafts, which are emerging now as a major factor in the regulation of anoikis and remain to be explored further. A better understanding of the molecular mechanisms involved in anoikis resistance would assist in the development of anticancer drugs to eradicate circulating tumor cells and prevent tumor metastasis.

\section{Acknowledgment}

This work was supported by a Research Grant 0910050 from the National Cancer Center, Republic of Korea.

\section{References}

[1] C. M. Nelson and M. J. Bissell, "Of extracellular matrix, scaffolds, and signaling: tissue architecture regulates development, homeostasis, and cancer," Annual Review of Cell and Developmental Biology, vol. 22, pp. 287-309, 2006.

[2] J. S. Desgrosellier and D. A. Cheresh, "Integrins in cancer: biological implications and therapeutic opportunities," Nature Reviews Cancer, vol. 10, no. 1, pp. 9-22, 2010.

[3] S. M. Frisch and H. Francis, "Disruption of epithelial cell-matrix interactions induces apoptosis," Journal of Cell Biology, vol. 124, no. 4, pp. 619-626, 1994.

[4] M. L. Taddei, E. Giannoni, T. Fiaschi, and P. Chiarugi, "Anoikis: an emerging hallmark in health and diseases," Journal of Pathology, vol. 226, no. 2, pp. 380-393, 2012.

[5] C. D. Simpson, K. Anyiwe, and A. D. Schimmer, "Anoikis resistance and tumor metastasis," Cancer Letters, vol. 272, no. 2, pp. 177-185, 2008.

[6] T. Uekita, M. Tanaka, M. Takigahira et al., "CUB-domaincontaining protein 1 regulates peritoneal dissemination of gastric scirrhous carcinoma," American Journal of Pathology, vol. 172, no. 6, pp. 1729-1739, 2008.

[7] S. J. Strauss, T. Ng, A. Mendoza-Naranjo, J. Whelan, and P. H. B. Sorensen, "Understanding micrometastatic disease and anoikis resistance in ewing family of tumors and osteosarcoma," The Oncologist, vol. 15, no. 6, pp. 627-635, 2010.

[8] S. Masoumi Moghaddam, A. Amini, D. L. Morris, and M. H. Pourgholami, "Significance of vascular endothelial growth factor in growth and peritoneal dissemination of ovarian cancer," Cancer and Metastasis Reviews. In press.

[9] I. D. Campbell and M. J. Humphries, "Integrin structure, activation, and interactions," Cold Spring Harbor Perspectives in Biology, vol. 3, no. 3, 2011.

[10] L. D. Nagaprashantha, R. Vatsyayan, P. C. R. Lelsani, S. Awasthi, and S. S. Singhal, "The sensors and regulators of cell-matrix surveillance in anoikis resistance of tumors," International Journal of Cancer, vol. 128, no. 4, pp. 743-752, 2011.

[11] T. Uekita and R. Sakai, "Roles of CUB domain-containing protein 1 signaling in cancer invasion and metastasis," Cancer Science, vol. 102, no. 11, pp. 1943-1948, 2011.

[12] T. Uekita, L. Jia, M. Narisawa-Saito, J. Yokota, T. Kiyono, and R. Sakai, "CUB domain-containing protein 1 is a novel regulator of anoikis resistance in lung adenocarcinoma," Molecular and Cellular Biology, vol. 27, no. 21, pp. 7649-7660, 2007.

[13] H. Liu, S. E. Ong, K. Badu-Nkansah, J. Schindler, F. M. White, and R. O. Hynes, "CUB-domain-containing protein 1 (CDCP1) activates Src to promote melanoma metastasis," Proceedings of the National Academy of Sciences of the United States of America, vol. 108, no. 4, pp. 1379-1384, 2011.

[14] M. E. Guicciardi and G. J. Gores, "Life and death by death receptors," The FASEB Journal, vol. 23, no. 6, pp. 1625-1637, 2009.

[15] P. Chiarugi and E. Giannoni, "Anoikis: a necessary death program for anchorage-dependent cells," Biochemical Pharmacology, vol. 76, no. 11, pp. 1352-1364, 2008.

[16] A. Marconi, P. Atzei, C. Panza et al., "FLICE/caspace-8 activation triggers anoikis induced by $\beta$ 1-integrin blockade in human keratinocytes," Journal of Cell Science, vol. 117, no. 24, pp. 5815-5823, 2004.

[17] F. Aoudjit and K. Vuori, "Matrix attachment regulates Fasinduced apoptosis in endothelial cells: a role for c-Flip and implications for anoikis," Journal of Cell Biology, vol. 153, no. 3, pp. 633-643, 2001.

[18] D. G. Stupack, X. S. Puente, S. Boutsaboualoy, C. M. Storgard, and D. A. Cheresh, "Apoptosis of adherent cells by recruitment of caspase- 8 to unligated integrins," Journal of Cell Biology, vol. 155, no. 4, pp. 459-470, 2001.

[19] I. A. Mawji, C. D. Simpson, M. Gronda et al., "A chemical screen identifies anisomycin as an anoikis sensitizer that functions by decreasing FLIP protein synthesis," Cancer Research, vol. 67, no. 17, pp. 8307-8315, 2007.

[20] J. Chen, T. Li, Y. Wu et al., "Prognostic significance of vascular endothelial growth factor expression in gastric carcinoma: a meta-analysis," Journal of Cancer Research and Clinical Oncology, vol. 137, no. 12, pp. 1799-1812, 2011.

[21] W. Hong-Xia, L. Xiu-Mei, H. Xiu-Hua, J. Ya-Jun, Z. Gui-Hua, and Z. Wan-Chuan, "Clinical significance of tissue factor and vascular endothelial growth factor expressions on CD14 + monocytes in patients with non-hodgkin lymphoma," 
Zhongguo Yi Xue Ke Xue Yuan Xue Bao, vol. 33, no. 4, pp. 427-431, 2011.

[22] Y. z. Xu, Y. Zhu, Z. j. Shen et al., "Significance of heparanase1 and vascular endothelial growth factor in adrenocortical carcinoma angiogenesis: potential for therapy," Endocrine, vol. 40, no. 3, pp. 427-431, 2011.

[23] N. T. Woods, H. Yamaguchi, F. Y. Lee, K. N. Bhalla, and H. G. Wang, "Anoikis, initiated by MCL-1 degradation and Bim induction, is deregulated during oncogenesis," Cancer Research, vol. 67, no. 22, pp. 10744-10752, 2007.

[24] J. Y. Kim, B. N. Bae, J. E. Kwon, H. J. Kim, and K. Park, "Prognostic significance of epidermal growth factor receptor and vascular endothelial growth factor receptor in colorectal adenocarcinoma," APMIS, vol. 119, no. 7, pp. 449-459, 2011.

[25] N. Fujimoto, K. Gemba, and T. Kishimoto, "Clinical significance of serum vascular endothelial growth factor in malignant pleural mesothelioma," Journal of Thoracic Oncology, vol. 6, no. 5, pp. 971-972, 2011.

[26] D. Cheng, B. Liang, and H. Kong, "Clinical significance of vascular endothelial growth factor and endostatin levels in the differential diagnosis of malignant and benign ascites," Medical Oncology. In press.

[27] M. J. Reginato, K. R. Mills, J. K. Paulus et al., "Integrins and EGFR coordinately regulate the pro-apoptotic protein Bim to prevent anoikis," Nature Cell Biology, vol. 5, no. 8, pp. 733$740,2003$.

[28] K. A. Whelan, S. A. Caldwell, K. S. Shahriari et al., "Hypoxia suppression of Bim and Bmf blocks anoikis and luminal clearing during mammary morphogenesis," Molecular Biology of the Cell, vol. 21, no. 22, pp. 3829-3837, 2010.

[29] R. Kalluri and R. A. Weinberg, "The basics of epithelialmesenchymal transition," Journal of Clinical Investigation, vol. 119, no. 6, pp. 1420-1428, 2009.

[30] A. Nagafuchi, Y. Shirayoshi, and K. Okazaki, "Transformation of cell adhesion properties by exogenously introduced E-cadherin cDNA," Nature, vol. 329, no. 6137, pp. 341-343, 1987.

[31] K. M. Hajra and E. R. Fearon, "Cadherin and catenin alterations in human cancer," Genes Chromosomes and Cancer, vol. 34, no. 3, pp. 255-268, 2002.

[32] B. De Craene, B. Gilbert, C. Stove, E. Bruyneel, F. Van Roy, and G. Berx, "The transcription factor snail induces tumor cell invasion through modulation of the epithelial cell differentiation program," Cancer Research, vol. 65, no. 14, pp. 6237-6244, 2005.

[33] T. Shirakihara, M. Saitoh, and K. Miyazono, "Differential regulation of epithelial and mesenchymal markers by $\delta \mathrm{EF} 1$ proteins in epithelial-mesenchymal transition induced by TGF- $\beta$," Molecular Biology of the Cell, vol. 18, no. 9, pp. 35333544, 2007.

[34] S. A. Mani, W. Guo, M. J. Liao et al., "The epithelialmesenchymal transition generates cells with properties of stem cells," Cell, vol. 133, no. 4, pp. 704-715, 2008.

[35] G. Li, K. Satyamoorthy, and M. Herlyn, "N-cadherinmediated intercellular interactions promote survival and migration of melanoma cells," Cancer Research, vol. 61, no. 9, pp. 3819-3825, 2001.

[36] T. T. Onder, P. B. Gupta, S. A. Mani, J. Yang, E. S. Lander, and R. A. Weinberg, "Loss of E-cadherin promotes metastasis via multiple downstream transcriptional pathways," Cancer Research, vol. 68, no. 10, pp. 3645-3654, 2008.

[37] P. W. B. Derksen, X. Liu, F. Saridin et al., "Somatic inactivation of E-cadherin and p53 in mice leads to metastatic lobular mammary carcinoma through induction of anoikis resistance and angiogenesis," Cancer Cell, vol. 10, no. 5, pp. 437-449, 2006.

[38] J. Yang, S. A. Mani, J. L. Donaher et al., "Twist, a master regulator of morphogenesis, plays an essential role in tumor metastasis," Cell, vol. 117, no. 7, pp. 927-939, 2004.

[39] M. A. Smit, T. R. Geiger, J. Y. Song, I. Gitelman, and D. S. Peeper, "A twist-snail axis critical for TrkBinduced epithelial-mesenchymal transition-like transformation, anoikis resistance, and metastasis," Molecular and Cellular Biology, vol. 29, no. 13, pp. 3722-3737, 2009.

[40] S. Spaderna, O. Schmalhofer, M. Wahlbuhl et al., "The transcriptional repressor ZEB1 promotes metastasis and loss of cell polarity in cancer," Cancer Research, vol. 68, no. 2, pp. 537-544, 2008.

[41] Y. Takeyama, M. Sato, M. Horio et al., "Knockdown of ZEB1, a master epithelial-to-mesenchymal transition (EMT) gene, suppresses anchorage-independent cell growth of lung cancer cells," Cancer Letters, vol. 296, no. 2, pp. 216-224, 2010.

[42] M. A. Smit and D. S. Peeper, "Zeb1 is required for TrkBinduced epithelial-mesenchymal transition, anoikis resistance and metastasis," Oncogene, vol. 30, no. 35, pp. 37353744, 2011.

[43] S. Kumar, S. H. Park, B. Cieply et al., "A pathway for the control of anoikis sensitivity by E-cadherin and epithelial-tomesenchymal transition," Molecular and Cellular Biology, vol. 31, no. 19, pp. 4036-4051, 2011.

[44] S. Shin, C. A. Dimitri, S. O. Yoon, W. Dowdle, and J. Blenis, "ERK2 but not ERK1 induces epithelial-to-mesenchymal transformation via DEF motif-dependent signaling events," Molecular Cell, vol. 38, no. 1, pp. 114-127, 2010.

[45] T. Shirakihara, K. Horiguchi, K. Miyazawa et al., "TGF- $\beta$ regulates isoform switching of FGF receptors and epithelialmesenchymal transition," EMBO Journal, vol. 30, no. 4, pp. 783-795, 2011.

[46] R. B. Hazan, R. Qiao, R. Keren, I. Badano, and K. Suyama, "Cadherin switch in tumor progression," Annals of the New York Academy of Sciences, vol. 1014, pp. 155-163, 2004.

[47] K. Araki, T. Shimura, H. Suzuki et al., "E/N-cadherin switch mediates cancer progression via TGF- $\beta$-induced epithelialto-mesenchymal transition in extrahepatic cholangiocarcinoma," British Journal of Cancer, vol. 105, no. 12, pp. 18851893, 2011.

[48] M. E. Diamond, L. Sun, A. J. Ottaviano, M. J. Joseph, and H. G. Munshi, "Differential growth factor regulation of Ncadherin expression and motility in normal and malignant oral epithelium," Journal of Cell Science, vol. 121, no. 13, pp. 2197-2207, 2008.

[49] S. V. Sharma, D. W. Bell, J. Settleman, and D. A. Haber, "Epidermal growth factor receptor mutations in lung cancer," Nature Reviews Cancer, vol. 7, no. 3, pp. 169-181, 2007.

[50] K. K. Haenssen, S. A. Caldwell, K. S. Shahriari et al., "ErbB2 requires integrin $\alpha 5$ for anoikis resistance via Src regulation of receptor activity in human mammary epithelial cells," Journal of Cell Science, vol. 123, no. 8, pp. 1373-1382, 2010.

[51] A. R. Grassian, Z. T. Schafer, and J. S. Brugge, "ErbB2 stabilizes Epidermal Growth Factor Receptor (EGFR) expression via Erk and sprouty2 in extracellular matrix-detached cells," Journal of Biological Chemistry, vol. 286, no. 1, pp. 79-90, 2011. 
[52] Z. T. Schafer, A. R. Grassian, L. Song et al., "Antioxidant and oncogene rescue of metabolic defects caused by loss of matrix attachment," Nature, vol. 461, no. 7260, pp. 109-113, 2009.

[53] K. Rosen, M. L. Coll, A. Li, and J. Filmus, "Transforming growth factor- $\alpha$ prevents detachment-induced inhibition of c-Src kinase activity, Bcl-XL down-regulation, and apoptosis of intestinal epithelial cells," Journal of Biological Chemistry, vol. 276, no. 40, pp. 37273-37279, 2001.

[54] H. G. Kang, J. M. Jenabi, J. Zhang et al., "E-cadherin cellcell adhesion in Ewing tumor cells mediates suppression of anoikis through activation of the ErbB4 tyrosine kinase," Cancer Research, vol. 67, no. 7, pp. 3094-3105, 2007.

[55] T. L. Yuan and L. C. Cantley, "PI3K pathway alterations in cancer: variations on a theme," Oncogene, vol. 27, no. 41, pp. 5497-5510, 2008.

[56] G. Yonglian, Z. Siwei, and Y. Zhangqun, "Induction of anoikis by phosphatase activity-dependent PTEN in human bladder transitional carcinoma cells BIU-87," Acta Medicinae Universitatis Scientiae et Technologiae Huazhong, vol. 2008, no. $5,2008$.

[57] M. A. Davies, Y. Lu, T. Sano et al., "Adenoviral transgene expression of MMAC/PTEN in human glioma cells inhibits Akt activation and induces anoikis," Cancer Research, vol. 58, no. 23, pp. 5285-5290, 1998.

[58] M. I. Vitolo, M. B. Weiss, M. Szmacinski et al., "Deletion of PTEN promotes tumorigenic signaling, resistance to anoikis, and altered response to chemotherapeutic agents in human mammary epithelial cells," Cancer Research, vol. 69, no. 21, pp. 8275-8283, 2009.

[59] J. T. Yu, R. G. Foster, and D. C. Dean, "Transcriptional repression by $\mathrm{Rb}-\mathrm{E} 2 \mathrm{~F}$ and regulation of anchorage-independent survival," Molecular and Cellular Biology, vol. 21, no. 10, pp. 3325-3335, 2001.

[60] B. Valentinis, A. Morrione, F. Peruzzi, M. Prisco, K. Reiss, and R. Baserga, "Anti-apoptotic signaling of the IGF-I receptor in fibroblasts following loss of matrix adhesion," Oncogene, vol. 18, no. 10, pp. 1827-1836, 1999.

[61] D. Sachdev, X. Zhang, I. Matise, M. Gaillard-Kelly, and D. Yee, "The type i insulin-like growth factor receptor regulates cancer metastasis independently of primary tumor growth by promoting invasion and survival," Oncogene, vol. 29, no. 2, pp. 251-262, 2010.

[62] R. F. Hwang, K. Yokoi, C. D. Bucana et al., "Inhibition of platelet-derived growth factor receptor phosphorylation by STI571 (Gleevec) reduces growth and metastasis of human pancreatic carcinoma in an orthotopic nude mouse model," Clinical Cancer Research, vol. 9, no. 17, pp. 6534-6544, 2003.

[63] N. G. Dolloff, S. S. Shulby, A. V. Nelson et al., "Bonemetastatic potential of human prostate cancer cells correlates with Akt/PKB activation by $\alpha$ platelet-derived growth factor receptor," Oncogene, vol. 24, no. 45, pp. 6848-6854, 2005.

[64] B. Westermark, A. Johnsson, and Y. Paulsson, "Human melanoma cell lines of primary and metastatic origin express the genes encoding the chains of platelet-derived growth factor (PDGF) and produce a PDGF-like growth factor," Proceedings of the National Academy of Sciences of the United States of America, vol. 83, no. 19, pp. 7197-7200, 1986.

[65] L. Wei, Y. Yang, X. Zhang, and Q. Yu, "Altered regulation of Src upon cell detachment protects human lung adenocarcinoma cells from anoikis," Oncogene, vol. 23, no. 56, pp. 90529061, 2004.
[66] M. Jechlinger, A. Sommer, R. Moriggl et al., "Autocrine PDGFR signaling promotes mammary cancer metastasis," Journal of Clinical Investigation, vol. 116, no. 6, pp. 15611570, 2006.

[67] J. C. Horowitz, D. S. Rogers, V. Sharma et al., "Combinatorial activation of FAK and AKT by transforming growth factor$\beta 1$ confers an anoikis-resistant phenotype to myofibroblasts," Cellular Signalling, vol. 19, no. 4, pp. 761-771, 2007.

[68] S. Uttamsingh, X. Bao, K. T. Nguyen et al., "Synergistic effect between EGF and TGF- $\beta 1$ in inducing oncogenic properties of intestinal epithelial cells," Oncogene, vol. 27, no. 18, pp. 2626-2634, 2008.

[69] D. Melisi, S. Ishiyama, G. M. Sclabas et al., "LY2109761, a novel transforming growth factor $\beta$ receptor type I and type II dual inhibitor, as a therapeutic approach to suppressing pancreatic cancer metastasis," Molecular Cancer Therapeutics, vol. 7, no. 4, pp. 829-840, 2008.

[70] W. Xian, L. Pappas, D. Pandya et al., "Fibroblast growth factor receptor 1-Transformed mammary epithelial cells are dependent on RSK activity for growth and survival," Cancer Research, vol. 69, no. 6, pp. 2244-2251, 2009.

[71] Q. Zeng, S. Chen, Z. You et al., "Hepatocyte growth factor inhibits anoikis in head and neck squamous cell carcinoma cells by activation of ERK and Akt signaling independent of NF $\kappa$ B," Journal of Biological Chemistry, vol. 277, no. 28, pp. 25203-25208, 2002.

[72] S. Watanabe, T. Kishimoto, and O. Yokosuka, "Hepatocyte growth factor inhibits anoikis of pancreatic carcinoma cells through phosphatidylinositol 3-kinase pathway," Pancreas, vol. 40, no. 4, pp. 608-614, 2011.

[73] I. Sher, S. A. Adham, J. Petrik, and B. L. Coomber, "Autocrine VEGF-A/KDR loop protects epithelial ovarian carcinoma cells from anoikis," International Journal of Cancer, vol. 124, no. 3, pp. 553-561, 2009.

[74] R. A. Cairns, I. S. Harris, and T. W. Mak, "Regulation of cancer cell metabolism," Nature Reviews Cancer, vol. 11, no. 2, pp. 85-95, 2011.

[75] O. Warburg, "On the origin of cancer cells," Science, vol. 123, no. 3191, pp. 309-314, 1956.

[76] R. L. Elstrom, D. E. Bauer, M. Buzzai et al., "Akt stimulates aerobic glycolysis in cancer cells," Cancer Research, vol. 64, no. 11, pp. 3892-3899, 2004.

[77] Y. Fan, K. G. Dickman, and W. X. Zong, "Akt and cMyc differentially activate cellular metabolic programs and prime cells to bioenergetic inhibition," Journal of Biological Chemistry, vol. 285, no. 10, pp. 7324-7333, 2010.

[78] G. L. Semenza, P. H. Roth, H. M. Fang, and G. L. Wang, "Transcriptional regulation of genes encoding glycolytic enzymes by hypoxia-inducible factor 1," Journal of Biological Chemistry, vol. 269, no. 38, pp. 23757-23763, 1994.

[79] G. L. Semenza, B. H. Jiang, S. W. Leung et al., "Hypoxia response elements in the aldolase A, enolase 1, and lactate dehydrogenase a gene promoters contain essential binding sites for hypoxia-inducible factor 1," Journal of Biological Chemistry, vol. 271, no. 51, pp. 32529-32537, 1996.

[80] A. Minchenko, I. Leshchinsky, I. Opentanova et al., "Hypoxia-inducible factor-1-mediated expression of the 6-phosphofructo-2-kinase/fructose-2,6-bisphosphatase-3 (PFKFB3) gene: its possible role in the warburg effect," Journal of Biological Chemistry, vol. 277, no. 8, pp. 61836187, 2002.

[81] J. W. Kim, I. Tchernyshyov, G. L. Semenza, and C. V. Dang, "HIF-1-mediated expression of pyruvate dehydrogenase 
kinase: a metabolic switch required for cellular adaptation to hypoxia," Cell Metabolism, vol. 3, no. 3, pp. 177-185, 2006.

[82] C. W. Lu, S. C. Lin, K. F. Chen, Y. Y. Lai, and S. J. Tsai, "Induction of pyruvate dehydrogenase kinase-3 by hypoxiainducible factor-1 promotes metabolic switch and drug resistance," Journal of Biological Chemistry, vol. 283, no. 42, pp. 28106-28114, 2008.

[83] K. Bensaad, A. Tsuruta, M. A. Selak et al., "TIGAR, a p53inducible regulator of glycolysis and apoptosis," Cell, vol. 126, no. 1, pp. 107-120, 2006.

[84] K. H. Vousden and K. M. Ryan, "P53 and metabolism," Nature Reviews Cancer, vol. 9, no. 10, pp. 691-700, 2009.

[85] S. Matoba, J. G. Kang, W. D. Patino et al., "p53 regulates mitochondrial respiration," Science, vol. 312, no. 5780, pp. 1650-1653, 2006.

[86] J. W. Kim, P. Gao, Y. C. Liu, G. L. Semenza, and C. V. Dang, "Hypoxia-inducible factor 1 and dysregulated c-Myc cooperatively induce vascular endothelial growth factor and metabolic switches hexokinase 2 and pyruvate dehydrogenase kinase 1," Molecular and Cellular Biology, vol. 27, no. 21, pp. 7381-7393, 2007.

[87] C. V. Dang, A. Le, and P. Gao, "MYC-induced cancer cell energy metabolism and therapeutic opportunities," Clinical Cancer Research, vol. 15, no. 21, pp. 6479-6483, 2009.

[88] R. G. Jones, D. R. Plas, S. Kubek et al., "AMP-activated protein kinase induces a p53-dependent metabolic checkpoint," Molecular Cell, vol. 18, no. 3, pp. 283-293, 2005.

[89] H. Ji, M. R. Ramsey, D. N. Hayes et al., "LKB1 modulates lung cancer differentiation and metastasis," Nature, vol. 448, no. 7155, pp. 807-810, 2007.

[90] D. B. Shackelford and R. J. Shaw, "The LKB1-AMPK pathway: metabolism and growth control in tumour suppression," Nature Reviews Cancer, vol. 9, no. 8, pp. 563-575, 2009.

[91] C. Fung, R. Lock, S. Gao, E. Salas, and J. Debnath, "Induction of autophagy during extracellular matrix detachment promotes cell survival," Molecular Biology of the Cell, vol. 19, no. 3, pp. 797-806, 2008.

[92] E. Gottlieb, "Cancer: the fat and the furious," Nature, vol. 461, no. 7260, pp. 44-45, 2009.

[93] R. Lock and J. Debnath, "Extracellular matrix regulation of autophagy," Current Opinion in Cell Biology, vol. 20, no. 5, pp. 583-588, 2008.

[94] M. T. Rosenfeldt and K. M. Ryan, "The multiple roles of autophagy in cancer," Carcinogenesis, vol. 32, no. 7, pp. 955963, 2011.

[95] R. Lock, S. Roy, C. M. Kenific et al., "Autophagy facilitates glycolysis during Ras-mediated oncogenic transformation," Molecular Biology of the Cell, vol. 22, no. 2, pp. 165-178, 2011.

[96] M. A. Loza-Coll, S. Perera, W. Shi, and J. Filmus, "A transient increase in the activity of Src-family kinases induced by cell detachment delays anoikis of intestinal epithelial cells," Oncogene, vol. 24, no. 10, pp. 1727-1737, 2005.

[97] E. Giannoni, T. Fiaschi, G. Ramponi, and P. Chiarugi, "Redox regulation of anoikis resistance of metastatic prostate cancer cells: key role for Src and EGFR-mediated pro-survival signals," Oncogene, vol. 28, no. 20, pp. 2074-2086, 2009.

[98] P. Zhu, M. J. Tan, R. L. Huang et al., "Angiopoietin-like 4 protein elevates the prosurvival intracellular $\mathrm{O}_{2}-: \mathrm{H}_{2} \mathrm{O}_{2}$ ratio and confers anoikis resistance to tumors," Cancer Cell, vol. 19, no. 3, pp. 401-415, 2011.

[99] M. C. Guadamillas, A. Cerezo, and M. A. del Pozo, "Overcoming anoikis—pathways to anchorageindependent growth in cancer," Journal of Cell Science, vol. 124, no. 19, pp. 31893197, 2011.

[100] P. G. Lloyd and C. D. Hardin, "Caveolae in cancer: two sides of the same coin? Focus on "Hydrogen peroxide inhibits nonsmall cell lung cancer cell anoikis through the inhibition of caveolin-1 degradation"', American Journal of Physiology, vol. 300, no. 2, pp. C232-C234, 2011.

[101] S. Staubach and F. G. Hanisch, "Lipid rafts: signaling and sorting platforms of cells and their roles in cancer," Expert Review of Proteomics, vol. 8, no. 2, pp. 263-277, 2011.

[102] G. Fiucci, D. Ravid, R. Reich, and M. Liscovitch, "Caveolin1 inhibits anchorage-independent growth, anoikis and invasiveness in MCF-7 human breast cancer cells," Oncogene, vol. 21, no. 15, pp. 2365-2375, 2002.

[103] T. C. Thompson, S. A. Tahir, L. Li et al., "The role of caveolin1 in prostate cancer: clinical implications," Prostate Cancer and Prostatic Diseases, vol. 13, no. 1, pp. 6-11, 2010.

[104] S. Luanpitpong, S. J. Talbott, Y. Rojanasakul et al., "Regulation of lung cancer cell migration and invasion by reactive oxygen species and caveolin-1," Journal of Biological Chemistry, vol. 285, no. 50, pp. 38832-38840, 2010.

[105] D. Ravid, S. Maor, H. Werner, and M. Liscovitch, "Caveolin1 inhibits anoikis and promotes survival signaling in cancer cells," Advances in Enzyme Regulation, vol. 46, no. 1, pp. 163175, 2006.

[106] P. Chanvorachote, U. Nimmannit, Y. Lu, S. Talbott, B. H. Jiang, and Y. Rojanasakul, "Nitric oxide regulates lung carcinoma cell anoikis through inhibition of ubiquitinproteasomal degradation of caveolin-1," Journal of Biological Chemistry, vol. 284, no. 41, pp. 28476-28484, 2009.

[107] P. Rungtabnapa, U. Nimmannit, H. Halim, Y. Rojanasakul, and P. Chanvorachote, "Hydrogen peroxide inhibits nonsmall cell lung cancer cell anoikis through the inhibition of caveolin-1 degradation," American Journal of Physiology, vol. 300, no. 2, pp. C235-C245, 2011.

[108] M. A. Del Pozo, N. B. Alderson, W. B. Kiosses, H. H. Chiang, R. G. W. Anderson, and M. A. Schwartz, "Integrins regulate rac targeting by internalization of membrane domains," Science, vol. 303, no. 5659, pp. 839-842, 2004.

[109] E. K. Park, J. P. Mi, S. H. Lee et al., "Cholesterol depletion induces anoikis-like apoptosis via FAK down-regulation and caveolae internalization," Journal of Pathology, vol. 218, no. 3, pp. 337-349, 2009.

[110] Y. C. Li, M. J. Park, S. K. Ye, C. W. Kim, and Y. N. Kim, "Elevated levels of cholesterol-rich lipid rafts in cancer cells are correlated with apoptosis sensitivity induced by cholesterol-depleting agents," American Journal of Pathology, vol. 168, no. 4, pp. 1107-1118, 2006.

[111] Y. N. Kim, G. J. Wiepz, A. G. Guadarrama, and P. J. Bertics, "Epidermal growth factor-stimulated tyrosine phosphorylation of caveolin- 1. Enhanced caveolin-1 tyrosine phosphorylation following aberrant epidermal growth factor receptor status," Journal of Biological Chemistry, vol. 275, no. 11, pp. 7481-7491, 2000.

[112] M. A. del Pozo, N. Balasubramanian, N. B. Alderson et al., "Phospho-caveolin-1 mediates integrin-regulated membrane domain internalization," Nature Cell Biology, vol. 7, no. 9, pp. 901-908, 2005.

[113] S. H. Lee, K. H. Koo, J. W. Park et al., "HIF-1 is induced via EGFR activation and mediates resistance to anoikislike cell death under lipid rafts/caveolae-disrupting stress," Carcinogenesis, vol. 30, no. 12, pp. 1997-2004, 2009. 
[114] Q. Huang, H. M. Shen, G. Shui, M. R. Wenk, and C. N. Ong, "Emodin inhibits tumor cell adhesion through disruption of the membrane lipid raft-associated integrin signaling pathway," Cancer Research, vol. 66, no. 11, pp. 5807-5815, 2006.

[115] J. Cai, X. Niu, Y. Chen et al., "Emodin-induced generation of reactive oxygen species inhibits RhoA activation to sensitize gastric carcinoma cells to anoikis," Neoplasia, vol. 10, no. 1, pp. 41-51, 2008.

[116] H. Z. Lee, W. H. Yang, M. J. Hour et al., "Photodynamic activity of aloe-emodin induces resensitization of lung cancer cells to anoikis," European Journal of Pharmacology, vol. 648, no. 1-3, pp. 50-58, 2010.

[117] R. Lasserre, X. J. Guo, F. Conchonaud et al., "Raft nanodomains contribute to Akt/PKB plasma membrane recruitment and activation," Nature Chemical Biology, vol. 4, no. 9, pp. 538-547, 2008. 

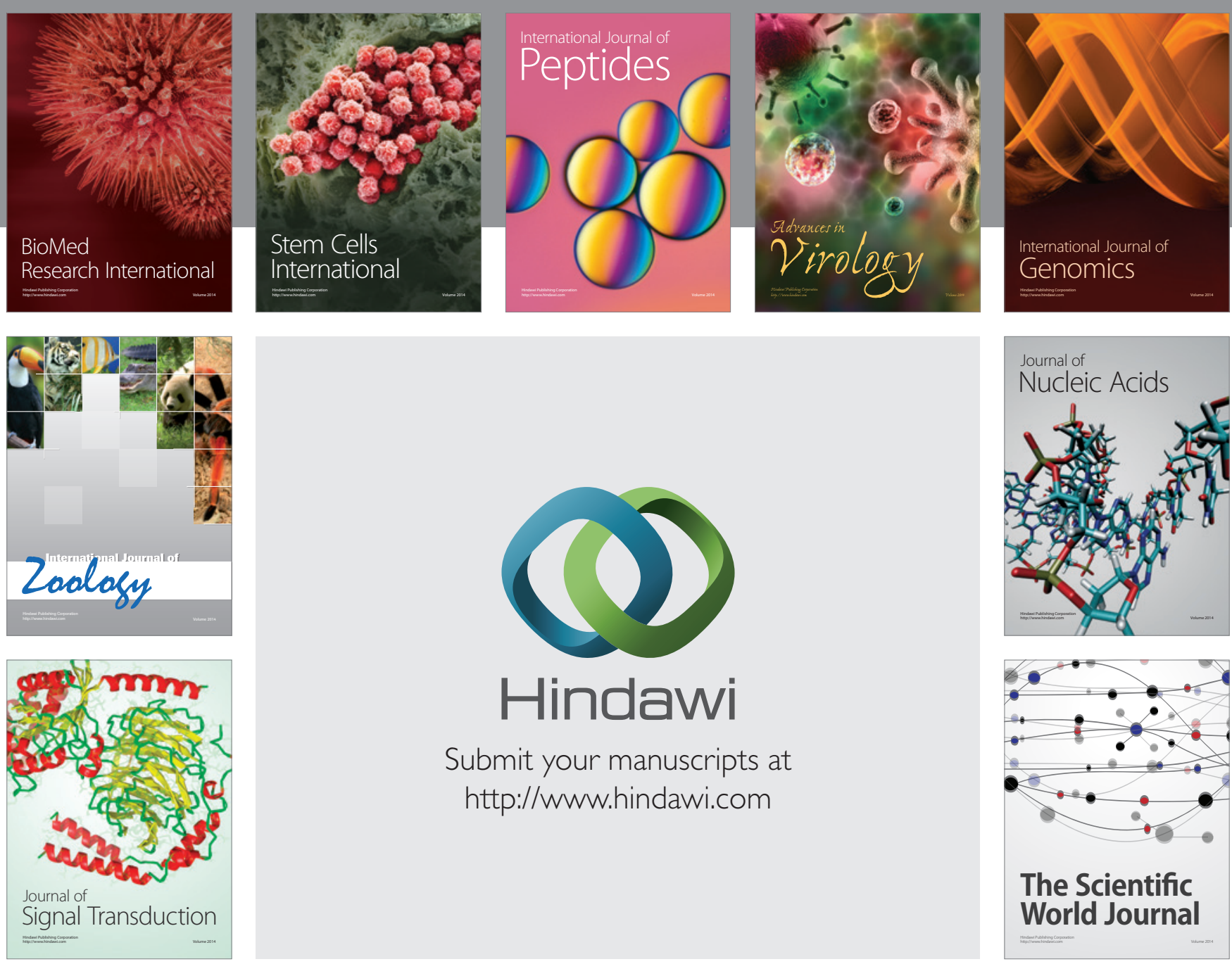

Submit your manuscripts at

http://www.hindawi.com
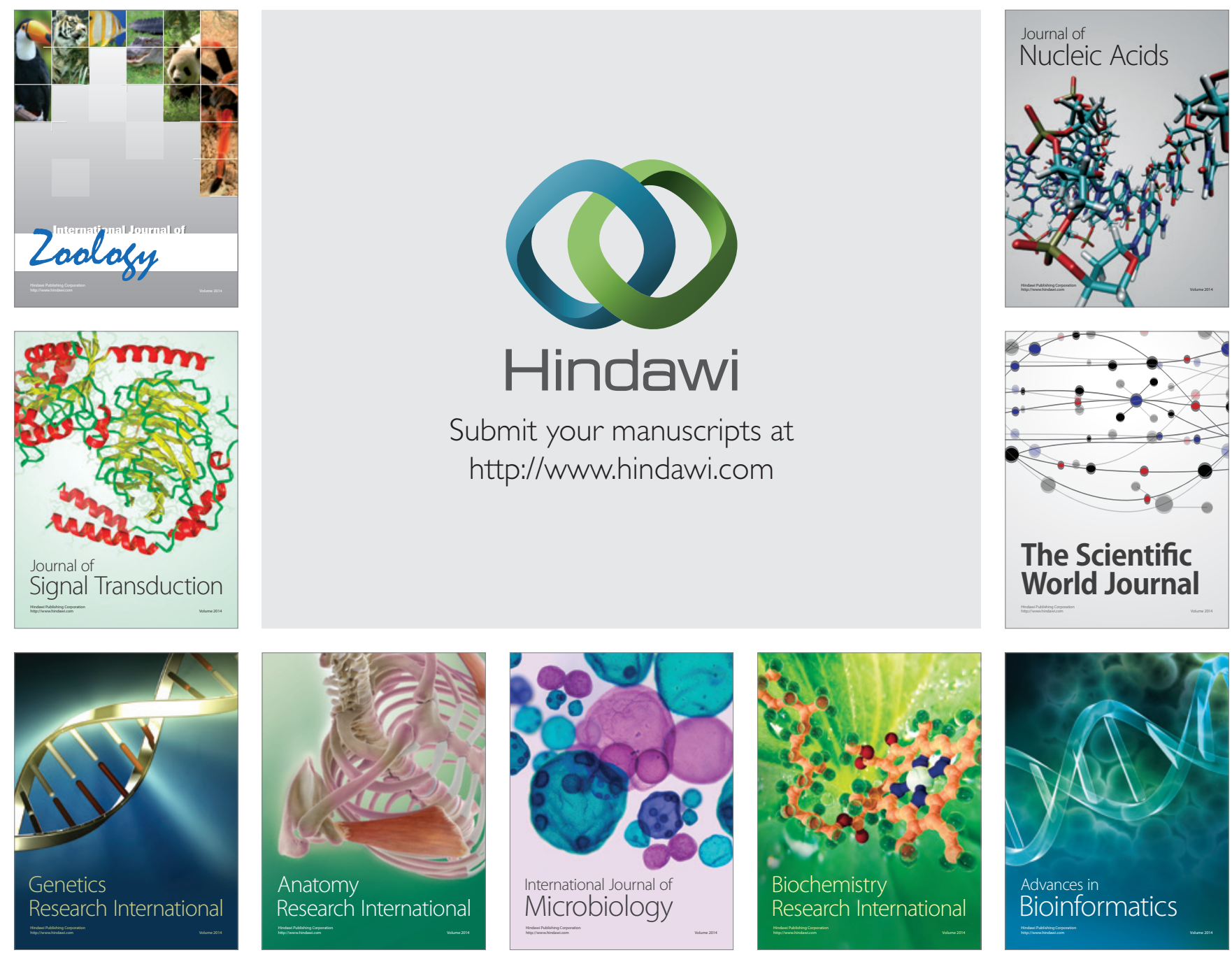

The Scientific World Journal
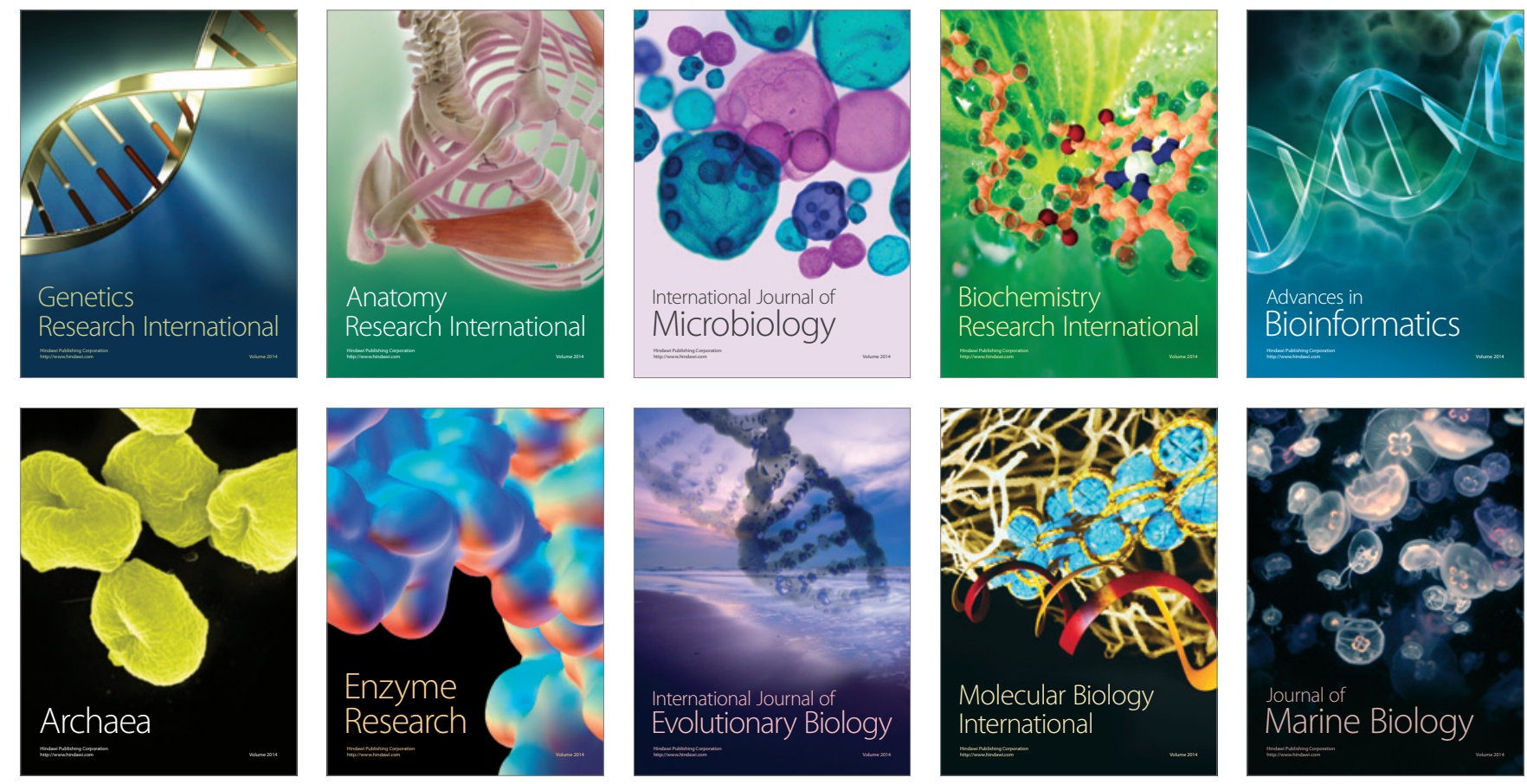